05.1

\title{
Влияние коллективных эффектов на концентрационную зависимость предела текучести сплавов при высокоэнергетических воздействиях
}

\author{
(C) В.В. Малашенко \\ Донецкий физико-технический институт им. А.А. Галкина, Донецк, Украина \\ Донецкий национальный университет, Донецк, Украина \\ E-mail: malashenko@fti.dn.ua
}

Поступило в Редакцию 28 мая 2020 г.

В окончательной редакции 28 мая 2020 г.

Принято к публикации 18 июня 2020 г.

Теоретически проанализирована высокоскоростная деформация состаренных сплавов. В рамках единого подхода объяснены различные типы концентрационной зависимости предела текучести, наблюдающиеся в эксперименте.

Ключевые слова: дислокации, точечные дефекты, высокоскоростная пластическая деформация, предел текучести.

DOI: 10.21883/PJTF.2020.18.50001.18399

Металлические сплавы получили широкое распространение в различных видах промышленности и относятся к весьма важному виду функциональных материалов. Одним из эффективных методов изменения их механических свойств является применение легирующих добавок. Влияние концентрации этих добавок при квазистатической деформации изучено довольно хорошо. Однако в случае высокоэнергетических воздействий, при которых материалы подвергаются высокоскоростной деформации, а дислокации совершают надбарьерное скольжение, зависимость механических свойств от концентрации легирующих примесей становится более сложной, поскольку во многом определяется различными динамическими эффектами. Высокоэнергетическое воздействие реализуется при динамическом канальноугловом прессовании, воздействии лазерными импульсами высокой мощности и высокоэнергетическими корпускулярными потоками, высокоскоростной обработке, в экспериментах по пробиванию оболочек, а также при использовании взрывов для сварки и обработки материалов [1-9].

Исследование влияния легирующих примесей на свойства сплавов чаще всего выполняется с помощью метода молекулярной динамики [10-12], однако концентрационные зависимости механических свойств в этих работах получены не были. В ряде работ такие процессы изучались на основе теории динамического взаимодействия, были получены аналитические выражения концентрационных зависимостей для некоторых частных случаев $[13,14]$. В настоящей работе в рамках единого подхода построена полная картина различных видов концентрационной зависимости, определяемая конкуренцией взаимодействия дислокаций с различными структурными дефектами.

Теория динамического взаимодействия структурных дефектов [13-18] основана на модифицированной струн- ной модели Гранато-Люкке. При высокоскоростной деформации (high strain rate deformation) механизм диссипации заключается в необратимом переходе кинетической энергии поступательного движения дислокации в энергию ее изгибных колебаний в плоскости скольжения, которые возникают в результате взаимодействия с другими структурными дефектами. В случае исследуемых нами сплавов это легирующие добавки и зоны Гинье-Престона, возникающие при старении сплавов. Данный механизм весьма чувствителен к виду спектра дислокационных колебаний, прежде всего к наличию в нем щели:

$$
\omega^{2}\left(q_{z}\right)=c^{2} q_{z}^{2}+\Delta^{2} .
$$

Здесь $c$ - скорость распространения в кристалле поперечных звуковых волн, $\omega$ - частота дислокационных колебаний, $\Delta-$ щель, $q_{z}-$ компонента волнового вектора (дислокация параллельна оси $O Z$ ).

Наличие щели в спектре дислокационных колебаний означает, что дислокация совершает колебания в параболической потенциальной яме. Однако эта яма перемещается по кристаллу вместе с колеблющейся дислокацией. Такая яма может возникать в результате действия сил изображения в приповерхностном слое, магнитоупругого взаимодействия с магнитной подсистемой кристалла, а также в результате коллективного взаимодействия точечных дефектов и дислокаций ансамбля с каждой движущейся дислокацией [13-18]. В нашем случае щель в спектре формируется в результате конкуренции двух последних взаимодействий, т. е. коллективного взаимодействия легирующих примесей с дислокацией и коллективного взаимодействия дислокаций ансамбля.

Одна из причин изменения характера концентрационной зависимости при увеличении концентрации заключается в следующем. С одной стороны, увеличение концентрации примесей приводит к росту динамического торможения. С другой стороны, с ростом концентрации 
увеличивается и величина спектральной щели, в результате эффективность торможения снижается.

Механические свойства материала определяются полной (total) силой динамического торможения (drag) дислокации. В нашем случае эта сила равна

$$
F_{t}=F_{d}+F_{G}+B v \text {. }
$$

Здесь $F_{d}$ - сила динамического торможения, обусловленная рассеянием энергии движущейся дислокации примесями, $F_{G}-$ сила торможения дислокации зонами Гинье-Престона, $B v-$ фононное торможение. Первое и второе слагаемые существенно зависят от вида спектральной щели [13-18]

$$
F=\frac{n b^{2}}{8 \pi^{2} m} \int d^{3} q\left|q_{x} \| \sigma_{x y}(\mathbf{q})\right|^{2} \delta\left(q_{x}^{2} v^{2}-\omega^{2}\left(q_{z}\right)\right) .
$$

Здесь $n$ - объемная концентрация соответствующего дефекта, $F$ - его вклад в полную силу торможения.

Концентрационная зависимость механических свойств зависит от того, какие структурные дефекты вносят главный вклад в формирование спектра дислокационных колебаний (1) и в величину полной силы торможения (2). Конкуренция этих взаимодействий позволяет объяснить различные типы такой зависимости, наблюдающиеся в экспериментах.

Пусть бесконечная краевая дислокация совершает скольжение под действием постоянного внешнего напряжения $\sigma_{0}$ в положительном направлении оси $O X$ с постоянной скоростью $v$ в плоскости XOZ. Кристалл содержит хаотически распределенные точечные дефекты и зоны Гинье-Престона. Зоны Гинье-Престона будем считать одинаковыми, имеющими радиус $R$ и распределенными случайным образом в плоскостях, параллельных плоскости скольжения дислокации XOZ.

Линии дислокаций параллельны оси $O Z$, их векторы Бюргерса $\mathbf{b}=(b, 0,0)$ одинаковы и параллельны оси $O X$. Положение $k$-й дислокации определяется функцией

$$
X_{k}=v t+w_{k}
$$

Здесь $w_{k}$ - случайная величина, описывающая изгибные колебания дислокации, возбужденные ее взаимодействием с хаотически распределенными дефектами. Среднее значение этой величины по длине дислокации и по хаотическому распределению дефектов равно нулю.

Уравнение движения дислокации может быть представлено в следующем виде:

$$
m\left\{\frac{\partial^{2} X}{\partial t^{2}}-c^{2} \frac{\partial^{2} X}{\partial z^{2}}\right\}=b\left[\sigma_{0}+\sigma_{x y}^{d}+\sigma_{x y}^{G}\right]-B \frac{\partial X}{\partial t},
$$

где $\sigma_{x y}^{d}$ - компонента тензора напряжений, создаваемых легирующими примесями на линии дислокации, $\sigma_{x y}^{G}-$ компонента тензора напряжений, создаваемых на линии дислокации зонами Гинье-Престона, $m$ - масса единицы длины дислокации (массы всех дислокаций считаем одинаковыми), $c$ - скорость распространения в кристалле поперечных звуковых волн, $B$ - константа демпфирования, обусловленная фононными, магнонными или электронными механизмами диссипации.

Рассмотрим случай, когда концентрация зон Гинье-Престона невысока либо они вообе отсутствуют, а главный вклад и в формирование спектральной щели, и в полную силу торможения вносит коллективное взаимодействие легирующих примесей с дислокацией. Он реализуется при условии

$$
n_{d}>n_{1}=\left(\frac{\rho b^{2}}{\chi}\right)^{2} \text {, }
$$

где $\chi-$ параметр несоответствия дефекта, $n_{d}-$ безразмерная концентрация точечных дефектов, $\rho$ плотность подвижных дислокаций. Спектральная щель в этом случае описывается выражением

$$
\Delta=\frac{c}{b}\left(n_{d} \chi^{2}\right)^{1 / 4} .
$$

Тогда динамический предел текучести пропорционален квадратному корню из концентрации легирующих примесей, что согласуется с экспериментальными данными [19]:

$$
\tau=\gamma \chi \sqrt{n_{d}}, \quad \gamma=\frac{\mu \dot{\varepsilon}}{\rho b c},
$$

где $\dot{\varepsilon}-$ скорость пластической деформации.

Рассмотрим случай, когда влияние зон Гинье-Престона по-прежнему несущественно и главный вклад в величину торможения вносят легирующие добавки. Вклад коллективного взаимодействия дислокаций ансамбля с каждой движущейся дислокацией доминирует при формировании спектральной щели. Это реализуется при $n_{d}<n_{1}$. Тогда спектральная щель определяется выражением $\Delta=c \sqrt{\rho}$. В этом случае концентрационная зависимость предела текучести является линейной

$$
\tau=\gamma \chi^{2} n_{d}
$$

Такая зависимость действительно наблюдалась в экспериментальной работе [20].

Если же концентрация зон Гинье-Престона высока и они оказывают существенное влияние на динамическое торможение дислокаций, концентрационная зависимость становится немонотонной, на ней появляются две восходящие ветви и одна нисходящая. Эта зависимость имеет максимум и минимум. На первом восходящем участке главный вклад в формирование щели вносят дислокации, а главный вклад в торможение - зоны Гинье-Престона. Предел текучести линейно растет с ростом концентрации примесей. После перехода через максимум главный вклад в формирование спектра вносят примеси, а главный вклад в торможение - зоны Гинье-Престона. С ростом концентрации примесей величина щели возрастает, а щель снижает эффективность торможения. Предел текучести на этом участке снижается. При дальнейшем 
увеличении концентрации после прохождения минимума примеси доминируют и при формировании спектра, и при торможении. Предел текучести снова растет:

$$
\tau=\frac{\eta}{\sqrt{1+\sqrt{n_{d} / n_{1}}}}+\frac{\beta n_{d}}{1+\sqrt{n_{d} / n_{1}}}+\lambda
$$

Здесь коэффициенты $\eta, \beta, \lambda$ зависят от плотности дислокаций и упругих констант кристалла, но не зависят от концентрации легирующих примесей. Концентрационная зависимость такого типа наблюдалась в работе [21].

Таким образом, теория динамического взаимодействия структурных дефектов позволяет не только получить аналитические выражения для вклада легирующих примесей в предел текучести сплавов, но и понять сущность физических процессов, протекающих при высокоскоростной деформации этих материалов.

\section{Конфликт интересов}

Автор заявляет, что у него нет конфликта интересов.

\section{Список литературы}

[1] Канель Г.И., Зарецкий Е.Б., Разоренов С.В., Аиитков С.И., Фортов В.Е. // УФН. 2017. Т. 187. № 5. C. $525-545$.

[2] Batani D. // EPL. 2016. V. 114. P. 65001(1-7).

[3] Малыгин Г.А., Клявин О.В. // ФТТ. 2017. Т. 59. В. 10. C. 1964-1969.

[4] Mayer P.N., Mayer A.E. // J. Appl. Phys. 2016. V. 120. P. 075901.

[5] Tramontina D., Bringa E., Erhart P., Hawreliak J., Germann T., Ravelo R., Higginbotham A., Suggit M., Wark J., Park N., Stukowski A., Tang Y. // High Energy Density Phys. 2014. V. 10. P. 9-15.

[6] Lee J., Veysset D., Singer J., Retsch M., Saini G., Pezeril T., Nelson K., Thomas E. // Nature Commun. 2012. V. 3. P. 1164.

[7] Zaretsky E.B., Kanel G.I. // J. Appl. Phys. 2013. V. 114. P. 083511.

[8] Канель Г.И., Фортов В.Е., Разоренов С.В. // УФН. 2007. T. 177. № 8. C. 809-830.

[9] Бородин И.Н., Майер А.Е. // ЖТФ. 2013. Т. 83. В. 8. C. $76-80$.

[10] Santos-Güemes R., Bellón B., Esteban-Manzanares G., Segurado J., Capolungo L., LLorca J. // Acta Mater. 2020. V. 188. P. 475-485.

[11] Esteban-Manzanares G., Alizadeh R., Papadimitriou I., Dickel D., Barrett C.D., LLorca J. // J. Mater. Sci. Eng. A. 2020. V. 788. P. 139555.

[12] Куксин А.Ю., Янилкин А.В. // МТТ. 2015. № 1. С. 54-65.

[13] Малашенко В.В. // ФТТ. 2019. Т. 61. В. 10. С. 1845-1848.

[14] Малашенко В.В. // Письма в ЖТФ. 2018. Т. 44. В. 18. C. 47-52.

[15] Malashenko V.V. // Physica B. 2009. V. 404. P. 3890-3892.

[16] Варюхин В.Н., Малашенко В.В. // Изв. РАН. Сер. физ. 2018. T. 82. № 9. C. 37-42.

[17] Малашенко В.В. // Письма в ЖТФ. 2016. Т. 42. В. 20. C. 1-5.
[18] Малашенко В.В. // Письма в ЖТФ. 2017. Т. 43. В. 17. C. $36-40$.

[19] Asay J.R., Fowles G.R., Durall G.E., Miles M.H., Tinder R.F. // J. Appl. Phys. 1972. V. 43. P. 2132-2145.

[20] Charit I., Seok C.S., Murty K.L. // J. Nucl. Mater. 2007. V. 361. P. 262-273.

[21] Morris D.G., Munoz-Morris M.A., Requejo L.M. // Mater. Sci. Eng. A. 2007. V. 460-461. P. 163-173. 